\title{
Continuing Board Certification: Seeing Our Way Forward
}

\author{
Grabam T. McMahon, MD, MMSc and Warren P. Newton, MD, MPH
}

Background: Traditionally the role of certifying boards has been to hold physicians accountable for demonstrating standards of competence. In recent years, the authority of continuing board certification has been challenged, due to multiple factors that have shifted the dynamics. The breadth and depth of new information, combined with the pressures of system barriers and administrative burdens, can make it challenging for clinicians stay current and maintain their own competency. Absent feedback about their performance, physicians presume they're practicing effectively. The resulting gap between confidence and competence can also lead physicians to make errors of which they may be unaware. In this environment, assessment and accountability are more important than ever.

Four Key Areas: The authors present four key areas to address to move forward with a board certification system that is effective, relevant, and respected. First, boards should set and communicate the specific expectations of specialists. Second, boards should use technology to create practice-relevant assessments. Third, they should collaborate with educators, while maintaining their distinct role as assessors. Fourth, boards need to establish and meet standards for professionalism and ethics that reflect their position as regulatory bodies.

Conclusion: Boards have a critical role in professional self-regulation. They should not compromise on their primary responsibility to set and evolve standards for competence and to conduct rigorous assessments of physicians. The methods boards use for assessments should evolve to meet the changing needs of physicians. Collaboration between educators and assessors provides more educational choice, relieves burdens, and supports physicians' commitment to lifelong learning. By working together with physicians, educators and assessors advance their shared goal of supporting physicians to work at the top of their capability and ultimately, optimize patient care. (J Am Board Fam Med 2020;33:S10-S14.)

Keywords: Certification, Continuing Medical Education, Medical Errors, Physicians, Professional Autonomy, Social Responsibility, Specialization

Pressures on physicians are growing exponentially. Patient care is increasingly complex and patient expectations are evolving. Family physicians are expected to see more patients while coping with ever-growing administrative burdens. They must keep up with the rapid pace of scientific developments, acquire emerging knowledge, and develop expertise in new skills. On top

This article was externally peer reviewed.

Submitted 27 November 2019; revised 14 April 2020; accepted 21 April 2020.

From the Accreditation Council for Continuing Medical Education (ACCME), Chicago, IL (GTM); American Board of Family Medicine (ABFM), Lexington, KY (WN).

Funding: None.

Conflicting and competing interests: Dr. Warren P. Newton is employed by the ABFM.

Corresponding author: Graham T. McMahon, MD, MMSc, Accreditation Council for Continuing Medical Education (ACCME), 401 N Michigan Ave \#1850, Chicago, IL 60611 (E-mail: gmcmahon@accme.org). of the multitude of professional obligations, physicians are also expected to balance personal and work responsibilities as well as maintain their wellbeing.

We know that physicians are motivated to achieve mastery, but this motivation is subject to countless competing pressures for their time and attention. The breadth and depth of new information, combined with the pressures of system barriers and administrative burdens, can make it challenging for clinicians to stay current and maintain their own competency and can lead physicians to make errors of which they may be unaware. ${ }^{1-3}$ Absent feedback about their performance or any errors, physicians can readily become complacent about their own professional development. With a rapidly changing medical field, the competencies and skills physicians developed in training and early in their careers diminish in importance, so reliance 
on prior (often distant) structured training as a reason for self confidence lacks legitimacy. While residents receive structured and intensive feedback, physicians in practice do not typically have access to similar feedback. A further challenge is that the process of unlearning outdated practices and then relearning new practices necessitates real effort (much greater than learning information or skills de novo), effort that accomplished professionals are unlikely to apply if they are overwhelmed, burned out, or if they believe they are already practicing effectively. ${ }^{4,5}$

In this environment, guidance, assessment, feedback, and accountability_including personal accountability-are more important than ever. Our profession faces critical questions: Do we have the humility to routinely submit ourselves to the judgment of our peers? To the judgment of our allied health professionals and patients? Will we accept responsibility for managing our professional competence and that of our colleagues? Are we willing to create a process for identifying and remediating colleagues who have room to grow? Who is responsible for determining physician competence and who is accountable to the public for those decisions?

\section{The Promise and Pitfalls of Certification}

Traditionally, the role of the certifying boards has been to set the standard for physician competence within their specialties and hold physicians accountable for demonstrating it. (This role builds on, but is distinct from, the role of licensing boards, which set requirements that physicians must meet to obtain and renew licenses to practice in their state. These requirements apply to all physicians and are not specialty specific.) Ideally, the boards serve as an external, independent, and trusted authority, placing patients' interests first, and providing value for a broad range of stakeholders including the public, physicians, credentialers, and employers. Boards are trusted to use a process that is reliable, accurate, objective, and fair for determining who can represent themselves as having specialist skills and who cannot.

In recent years, the authority, legitimacy, and relevance of the certifying boards has been the subject of acrimony. As would be anticipated for any accountability framework, the accusations vary. Some consider the examinations to be irrelevant to heir practice, to test competencies that do not matter; this attitude is partially driven by increased subspecialization. A variety of elements of the framework were administratively burdensome and were not considered to deliver value. Some resent the boards selling products that they mandate. Some object to the cost of preparing for and taking the assessments. Others have pointed out that a process that rejects so few lacks credibility. Some objected to any measurement of their performance or considered that there were no meaningful ways to characterize their performance and set standards toward it. Many recognized that the decennial examination had outlived its usefulness in an age where information and expectations are changing continuously. The complaints about board certification have generated media attention, lawsuits, and legislative initiatives designed to rein in the power of certifying boards. This negative attention has called into question the relevance and effectiveness of continuing board certification.

These arguments deserve to be listened to and evaluated. The work of the Continuing Board Certification: Vision for the Future Commission was intended to reevaluate the certification process and the boards' role and recommend strategies to ensure that certification remains-or becomes-an accountable and trusted system for determining competence. $^{6}$ But the Vision Commission report stopped short of holding the boards responsible for their most important responsibility and seems to have softened the boards' authority. The report said that the Commission supports the American Board of Medical Specialties (ABMS) member boards' key function in making summative decisions about the certification status of a diplomate and changing a diplomate's status when certification standards are not met. However, it characterized the core role of a board as one that "supports the ongoing commitment of diplomates to provide safe, high-quality, patient-centered care." ${ }^{\prime 7}$ The use of the word, "supports," diminishes rather than clarifies that the boards' primary responsibility is to determine which clinicians had been determined to be competent in providing safe, high-quality, patient centered care.

Will we as medical professionals, and our patients, really benefit if the certifying boards concede to the antiaccountability rancor by lowering standards? Perhaps a more appropriate response would be to raise standards - to meet the growing expectations and needs of the profession and the public in the 
rapidly changing health care environment. We see 4 key areas we need to address to move forward with a board certification system that is effective, relevant, and respected.

\section{Establish Reasonable Competency Expectations}

If physicians are to submit themselves to assessment of competency in their specialty, then they need to know the standards they are expected to meet. Boards should publish more than a blueprint; rather they should publish a list of the skills, expertise (in diagnosis, management, communication, team leadership, etc.), and level of quality that specialists in the discipline are expected to demonstrate. These expectations must be measurable and based on consensus from the specialist community; they must be regularly assessed for their continued relevance and must evolve in response to emerging science and changes in the health care system. Competency expectations should form the basis of the assessment and would be a powerful foundation for the education community, encouraging educators to move beyond imparting knowledge and focus on skill development and performance improvement.

By setting standards for competence that are relevant, measurable, and based on consensus from the specialist community, the boards have the opportunity to create incentives for physicians to engage in reflection, self-assessment, and lifelong professional development. Optimally, each board would set the competency expectations for physicians in their respective specialty areas; allow physicians to self-identify their core scope of practice within that discipline; assume responsibility for summative assessment (increasingly deployed longitudinally using educational technology); provide feedback to participants on their performance; and link physicians to recommended professional development activities developed by educational organizations when needed, recognizing engagement in a spectrum of learning activities, including those that help physicians reflect on and improve their practice.

\section{Prioritize Meaningful Decision Making}

Just as meaningful learning does not occur without effortful work, effective assessment is time consuming and challenging. Educational technology is rapidly advancing and enabling increasingly sophisticated insight into a range of individual competencies. ${ }^{8}$ Reasoning and medical decision making can now be readily assessed using evolving scenarios with incremental data. Adaptive technology can help certifying boards to create efficient, personalized assessments that are directly relevant to practice, correspond to patient needs, promote greater self awareness, and motivate participation in continuing medical education (CME) that will further improve physicians' competencies and skills.

The Commission's recommendation that ABMS boards move to "truly formative assessment approaches that are not high stakes nor highly secured formats" competes with the principle that assessors must prioritize summative decision making. ${ }^{3}$ Clearly, the methods used for summative assessments need to evolve-but these assessments must remain distinct from purely formative assessments. Formative approaches can and should be utilized, if they do not interfere with the priority of summative decision making. Formative feedback is critical for learning, and encourages learners to feel safe to make mistakes, get feedback on those areas that need growth, and then learn to do better. Summative decision making expects the opposite, that the physician demonstrate they meet the standard. Trying to combine both is inherently problematic, particularly if gaps identified during an assessment presented as formative are ultimately used to determine competence. $^{9}$

The words validity and reliability are surprisingly absent in the Vision Commission report. ${ }^{3}$ This is a remarkable absence for an assessment system that is meant to be based on measurable standards and evidence. ${ }^{10,11}$ Measurement that is not reliable or valid cannot generate useful inferences; thus, it is not only a waste of time and money, but also risks perpetuating physicians' erroneous self assessment. Threats to validity include assessments that allow unlimited time (which is clinically unrealistic), that do not take a reasonable approach to ensure the identity of the person completing it, or that allow groups to complete their assessments together. Some boards are exploring approaches that ask learners to find the answer in a given text or resource, which tests learners' comprehension skills, which are very distinct from the problem-solving and decision-making competencies that are likely to be more important to measure. It would be also important to test learners' ability to quickly access reliable information sources. Assessments that are either too easy, too difficult, or irrelevant to practice are also threats to validity and create cynicism.

Boards need to establish guidelines for ensuring that their competency requirements and processes 
are based on evidence, evaluated regularly, and improved as needed.

\section{Collaborate with Educators}

While education and training can be a component of a board's role, it is not their primary role-assessment is. Assessors and educators need to collaborate while maintaining distinct roles, if they are to fulfill their responsibilities to physicians and the public. ${ }^{12}$ Educators and certifying boards are increasingly working together to integrate education and assessment, applying a variety of techniques that are effective and efficient in engaging physicians, such as simulation, small-group problem solving, and reflective exercises. ${ }^{13}$ Educators support the role of assessors by communicating the standards for competence, identifying where physicians are falling short of the standard, and building educational programs to meet the needs of individuals and groups of physicians. Boards can communicate to educators the high-priority learning needs identified through assessments, helping educators design more relevant activities.

With these collaborations, physicians are able to meet multiple requirements for licensing and continuing certification through their participation at the same educational programs. This process helps to relieve burdens: the more certifying boards recognize participation in meaningful learning programs where CME (and continuing certification) is integrated with routine daily practice, the less burdensome this process will be. Participation data can be readily and securely shared between accredited educational providers and the boards using existing systems. Collaborations between boards and educators encourage physicians to take ownership of their learning agenda. Engagement in meaningful education and formative assessment can help to restore joy in learning and in our profession.

Just as assessment methods need to evolve to meet the needs of today's physicians, so do educational approaches. CME is undergoing a transformation, becoming a multidisciplinary approach for engaging physicians where they live, work, and learn. It is about creating learning experiences rather than providing information transfer; it is about nurturing teams, putting a mentor at a physician's elbow, giving physicians feedback at the bedside or in the clinic, employing simulation and other educational technology to support learning, and building longitudinal relationships between educators and physicians. ${ }^{14}$ New accreditation criteria recognize the achievements of accredited organizations that address priorities in patient safety, public health, and population health; collaborate with health systems and communities; create individualized learning plans; design education to optimize technical and procedural skills; leverage educational technology; and demonstrate meaningful educational and clinical outcomes. ${ }^{15} \mathrm{CME}$ is increasingly becoming the professional development vehicle that can help clinicians maintain competence and meet the requirements set by the boards. Through collaborations, boards and educators can continue to elevate the rigor and effectiveness of $\mathrm{CME}$.

\section{Be Fair, Equitable, and Transparent}

Just as we expect physicians to adhere to high standards for professionalism and ethics, we should expect certifying boards to hold themselves accountable. Boards need to establish and meet standards that reflect their position as regulatory bodies. They should establish cost-efficient systems, set reasonable fees, and follow best practices for nonprofit financial management.

Boards should be cautious not to mandate the purchase of their own educational products; they need to express the expectations of education and allow the broad community of educators to develop and deliver those services. This will provide more choice and flexibility for physicians, who could then choose the learning format and approach that is best for them.

The ABMS Web site says that "the ABMS and the ABMS Boards must have consistent processes and requirements for continuing certification that are fair, equitable, transparent, effective, and efficient." Is it fair-to physicians and the public - that the continuing certification process is mandatory for some physicians (based on when they completed their training, or age) to maintain their board certification, while it is voluntary for lifetime certificate holders and physicians not currently participating in the continuing certification process?

\section{Conclusion}

Boards have a critical role in professional self regulation. They should not compromise on their primary responsibility to set and evolve standards for competence for their specialty and to conduct rigorous assessments of physicians. The methods boards use for assessments should evolve to meet the changing needs of physicians and the health care environment. They should give feedback to 
physicians, help them identify where they have opportunities for growth, and direct them to relevant educational opportunities. Collaboration between educators and assessors provides more educational choice and diversity to physicians, relieves burdens, and supports physicians' commitment to lifelong learning.

By working together with physicians, educators and assessors advance their shared goal of supporting physicians to work at the top of their capability and ultimately, optimize patient care.

The responsibility for professional self regulation rests not only with the boards; it rests with all us. Participating in an accountability system may not personally benefit each of us; however, our participation is critical to make the system meaningful for all. This accountability is essential if we are to maintain the public's trust. Our contract with society depends on the integrity of each clinician and the profession as a whole; it involves placing patients' interests first and setting and maintaining standards of competence and integrity. Perhaps one outcome of the anger, angst, and debate over certification, and the Vision Commission's work, is that it will encourage us to consider our shared responsibilities for redesigning professional development. We are privileged to serve as members of the medical profession. By assuming responsibility for our own and each other's attainment and continuing competency, we manifest our commitment to our profession and to the people who trust us in their time of need.

To see this article online, please go to: http://jabfm.org/content/ 33/Supplement/S10.full.

\section{References}

1. Meyer AN, Payne VL, Meeks DW, Rao R, Singh H. Physicians' diagnostic accuracy, confidence, and resource requests: a vignette study. JAMA Intern Med 2013;173:1952-8.

2. Eva KW, Regehr G. Self-assessment in the health professions: a reformulation and research agenda. Acad Med 2005;80:S46-S54.
3. Gordon MJ. A review of the validity and accuracy of self-assessments in health professions training. Acad Med 1991;66:762-9.

4. Bonchek M. Why the problem with learning is unlearning. Harvard Business Review. Nov 3, 2016. Available from: https://hbr.org/2016/11/why-theproblem-with-learning-is-unlearning.

5. Lubelfeld M, Polyak N. The unlearning leader: leading for tomorrow's schools today. Available from: https://rowman.com/isbn/9781475833478.

6. Continuing Board certification: vision for the future. Goals and foundational assumptions. Available from: https://visioninitiative.org/about/goals-assumptions/. Accessed November 20, 2019.

7. Continuing Board certification: vision for the future. Final report. February 12, 2019. Available from: https://visioninitiative.org/wp-content/uploads/ 2019/02/Commission_Final_Report_20190212.pdf. Accessed November 20, 2019.

8. Newton WP, Rode K, O’Neill T, Fain R, Baxley E. Longitudinal assessment: where we are and why it is important. J Am Board Fam Med 2019;32:448-50.

9. Abruzzo D, Sklar DP, McMahon GT. Improving trust between learners and teachers in medicine. Acad Med 2019;94:147-50.

10. Wass V, Van der Vleuten C, Shatzer J, Jones R. Assessment of clinical competence. Lancet 2001;357 :945-9.

11. Epstein RM, Hundert EM. Defining and assessing professional competence. JAMA 2002;287:226-35.

12. Newton WP, Baxley E, Rode K, O’Neill T, Fain R. Improving continuing education for family physicians: the role of the American Board of Family Medicine. J Am Board Fam Med 2019;32:756-8.

13. Macario A, Harman AE, Hosansky T, Post ME, Sun H, McMahon GT. Evolving board certificationGlimpses of success. N Engl J Med 2019;380:115-8.

14. McMahon GT. The leadership case for investing in continuing professional development. Acad Med 2017;92:1075-7.

15. Accreditation Council for Continuing Medical Education. Menu of new criteria for accreditation with commendation. Published September 29, 2016. Available from: http://www.accme.org/sites/ default/files/2018-03/731_20180123_Menu_of_New_ Criteria_for_Accreditation_with_Commendation.pdf. Accessed November 20, 2019. 